\title{
Polyene Resistance and the Isolation of Sterol Mutants in Saccharomyces cerevisiae
}

\author{
By S. W. MOLZAHN AND R. A. WOODS \\ Department of Genetics, The University of Sheffield, Sheffield, S10 $2 T N$
}

(Accepted for publication 28 April I972)

\begin{abstract}
SUMMARY
Mutants of Saccharomyces cerevisiae have been selected for resistance to the polyene antibiotics, etruscomycin, filipin, nystatin, pimaricin and rimocidin. All mutants are resistant to nystatin and there are several patterns of cross-resistance. The mutants were allocated to four unlinked genes pol I, 2, 3 and 5. A fifth gene, pol 4, was recovered as a double mutant with a strain carrying the pol I mutation. The pol 4 mutation does not cause resistance. pol $I$ and pol 3 are allelic to the previously described nys $I$ and nys 3 (Ahmed \& Woods, I967). There are correlations between the polyene used for mutant isolation and (i) the extent of cross-resistance; (ii) the selection of mutants at particular pol genes. Ultraviolet absorption spectra of non-saponifiable material extracted from representative mutants showed that all five genes affect the sterol composition of the cell. The major sterols found in $\mathrm{pol}^{+}$are ergosterol and 24,(28)dehydroergosterol, the latter is not found in any of the mutants whilst ergosterol is lacking in pol 2 and only present at very low levels in pol 3. The spectra of extracts of pol $I$ and pol 3 indicate the presence of new sterols (Woods, I97I). Mutants of pol I excrete sterol into the growth medium. Studies on double mutants indicate epistasis between pol genes with respect to sterol pattern and suggest that they are metabolically related in the sequence pol $2 \rightarrow$ pol $3 \rightarrow$ pol $5 \rightarrow$ pol I $\rightarrow$ pol $4 \rightarrow \mathrm{pol}^{+}$. A rapid qualitative technique for the preparation of non-saponifiable extracts of yeast for sterol analysis is described.
\end{abstract}

\section{INTRODUCTION}

Ergosterol and 24,(28)dehydroergosterol are the major sterols found in Saccharomyces cerevisiae and other species of yeast (Breivik \& Owades, 1957). Whilst their precise metabolic roles are not clear, sterols are essential for the growth of yeast; during anaerobic growth they are not synthesized and must be supplied exogenously (Andreason \& Stier, 1953). Several attempts have been made to isolate sterol-deficient mutants of yeast but they have not been successful (Adelberg, Roslansky, Myers \& Coughlin, I955; Resnick \& Mortimer, I966).

Polyene antibiotics act by complexing with membrane sterols which severely disrupts cell permeability mechanisms (Lampen, 1966). There have been many reports of the isolation of polyene-resistant strains of fungi (Stout \& Pagano, 1956; Littman, Pisano \& Lancaster, 1958; Manning \& Robertson, 1959; Hebeka \& Solotorovsky, 1965; Stanley \& English, 1965) but there has been little reported research on the physiological and biochemical properties of such strains. The genetic analysis of nystatin resistance in yeast has been reported by Ahmed \& Woods (1967) and Patel \& Johnston (I968). The former authors were able to identify three resistance genes, nys $I$ to nys 3, and three dominant modifying genes $M^{\text {nys } I}$ to $M^{\text {nys }} 3$ (Ahmed \& Woods, I967; Woods \& Ahmed, I968). 
Since nystatin has been shown to complex with ergosterol in the yeast cell membrane (Lampen, Arnow, Borowska \& Laskin, 1962) it might be supposed that nystatin resistance would be associated with alterations in membrane sterol. Woods (197I) has confirmed this in a study of the sterol contents of mutants of nys $I$ and nys 3. Mutants of these two genes contain sterols which are not detected in wild-type sensitive strains and they do not appear to contain $24,(28)$ dehydroergosterol. In addition nys 3 mutants are deficient in ergosterol.

These findings suggested that polyene resistance, apart from its intrinsic importance, might be of considerable interest in that it allowed the recovery of sterol mutants of yeast. Since several polyene antibiotics are now available and have been shown to have differing affinities for a range of sterols (Zygmunt \& Tavormina, I966), it seemed appropriate to extend studies to include other polyenes. In this paper we report the isolation and characterization of mutants selected for resistance to etruscomycin, filipin, nystatin, pimaricin and rimocidin.

We have been able to identify three further genes affecting resistance and sterol composition. For convenience we have assigned them the genetic nomenclature pol, denoting polyene resistance, since they are of diverse origin. The genes nys $I$ and nys 3 have been renamed pol $\mathrm{I}$ and pol 3; nys 2 has been lost (Woods, I97I) and the linkage data for pol 2 indicates that it is a new locus.

\section{METHODS}

Strains and media. Two polyene-sensitive strains of Saccharomyces cerevisiae were selected from stocks synthesized by Dr K. A. Ahmed. They were derived from a single ascus, differ only in their mating type and do not carry any of the known resistance modifiers (Ahmed \& Woods, I967, Woods \& Ahmed, I968). These two strains are thus designated $\mathrm{pol}^{+}$. The standard strains of nys $I$ and nys 3 were the mutants nys $I b$ and nys $3 a$ described by Woods (I97I). The complete and minimal media (YCM and YMM) have been described previously (Lomax, Gross \& Woods, I97I).

Polyene antibiotics. Polyenes were stored at $-20{ }^{\circ} \mathrm{C}$. For use they were dissolved in absolute methanol except for nystatin which was dissolved in propylene glycol. Stock solutions were prepared containing $1000 \mu \mathrm{g} / \mathrm{ml}$ (I000 units $/ \mathrm{ml}$ for nystatin) and stored at $-20^{\circ} \mathrm{C}$ for no longer than I month. These stock solutions were added to medium to give the final concentrations listed in the text.

Growth conditions. Cultures for quantitative sterol analysis were grown for $48 \mathrm{~h}$ in $50 \mathrm{ml}$ of YCM in $250 \mathrm{ml}$ Erlenmeyer flasks on a rotary shaker at $200 \mathrm{rev} . / \mathrm{min}$. At this time $\mathrm{pol}^{+}$ strains are in stationary phase. The initial inoculum was taken from an overnight culture on YCM and adjusted to give $10^{6}$ cells $/ \mathrm{ml}$. Cultures for qualitative sterol analysis were grown for $48 \mathrm{~h}$ on solid YCM. All incubations were at $28^{\circ} \mathrm{C}$.

Mutant selection and isolation. An overnight culture of $\mathrm{pol}^{+}$on YCM was washed and resuspended in $\mathrm{IO} \mathrm{ml} 0.89 \%$ saline at about $\mathrm{IO}^{10}$ cells $/ \mathrm{ml}$. Ethyl methane sulphonate was added $(\mathrm{I} \%, \mathrm{v} / \mathrm{v})$ and the suspension was incubated on a rotary shaker at $200 \mathrm{rev} . / \mathrm{min}$ for $2 \mathrm{~h}$. The cells were harvested by centrifugation, washed twice in saline, and resuspended in YCM or YMM at about $2 \times 10^{6}$ cells $/ \mathrm{ml}$. Samples ( $\mathrm{I} \mathrm{ml}$ ) of this suspension were dispensed into sterile I $25 \times$ I I mm test tubes and incubated on the rotary shaker for $24 \mathrm{~h}$. The tubes were then centrifuged and the cell pellets resuspended in $\mathrm{I} .5 \mathrm{ml}$ of the same medium plus polyene and incubated for a further $24 \mathrm{~h}$. The cultures were then centrifuged and resuspended in fresh medium plus polyene. After a further $24 \mathrm{~h}$ incubation, samples were taken from each tube and plated on to solid medium plus the appropriate polyene. Only one resistant clone was selected from each tube, thus all of the mutants investigated are of independent origin. 
Genetic techniques. Matings and ascus dissections were performed as described previously (Ahmed \& Woods, 1967). Only complete tetrads were used in genetic analysis.

Polyene resistance tests. Qualitative tests for resistance were carried out on YCM or YMM supplemented with polyene at the following concentrations: nystatin, 5 units $/ \mathrm{ml}$; pimaricin, Io $\mu \mathrm{g} / \mathrm{ml}$; filipin, $\mathrm{I} \cdot 25 \mu \mathrm{g} / \mathrm{ml}$; etruscomycin, $2.5 \mu \mathrm{g} / \mathrm{ml}$; and rimocidin $2.5 \mu \mathrm{g} / \mathrm{ml}$. Strains under test were inoculated on to a masterplate and replicated on to medium plus polyene. The results were recorded at $24 \mathrm{~h}$ intervals for up to $96 \mathrm{~h}$. Sensitive strains showed negligible growth at these polyene concentrations. Since all mutants were resistant to nystatin (see later) this polyene was employed for all routine tests for resistance.

\section{Sterol analyses}

Cells. Quantitative analysis. Non-saponifiable sterols were extracted and quantified by the method of Breivik \& Owades (1957) as described by Woods (I97I).

Cells. Qualitative analysis. To facilitate sterol analysis of the large numbers of segregants necessary for genetic analysis we devised the following modification of the above technique. Cultures were grown for $48 \mathrm{~h}$ on YCM and samples (approx $35 \mathrm{mg}$ wet wt) suspended in $3 \mathrm{ml} \mathrm{40} \%$ alcoholic $\mathrm{KOH}$ in $\mathrm{I} 5 \times \mathrm{I} 50 \mathrm{~mm}$ test tubes with plastic caps. The tubes were heated at 85 to $90{ }^{\circ} \mathrm{C}$ for $30 \mathrm{~min}$ and then allowed to cool to room temperature. After addition of I $\mathrm{ml}$ water the non-saponifiable materials were extracted into $5 \mathrm{ml} n$-heptane. The aqueous layer was then removed by aspiration and the absorption spectrum of the heptane layer between 310 and $200 \mathrm{~nm}$ recorded on a Beckman DB spectrophotometer coupled to a Io inch chart recorder.

Growth medium samples. Analyses of growth media were performed in parallel with the quantitative analyses of cells. The saponification mixture consisted of $25 \mathrm{ml}$ medium, Io $\mathrm{ml}$ $40 \%$ alcoholic $\mathrm{KOH}$ and $\mathrm{IO} \mathrm{ml}$ absolute ethanol in a $100 \mathrm{ml}$ measuring cylinder securely capped with aluminium foil. The mixture was heated at 85 to $90^{\circ} \mathrm{C}$ for $\mathrm{I} \cdot 5 \mathrm{~h}$ and allowed to cool to room temperature. After the addition of $16 \mathrm{ml}$ water the sterols were extracted in Io $\mathrm{ml} n$-heptane. Absorption spectra were recorded from the undiluted heptane extracts.

Liebermann-Burchard assay. This sterol assay (Stadtman, 1957) was performed on extracts prepared from cells and growth medium by the quantitative methods described above. Samples of the heptane extracts $(0.2 \mathrm{ml}$ for cells and $2.0 \mathrm{ml}$ for growth medium) were evaporated to dryness and redissolved in $3 \mathrm{ml}$ chloroform. Liebermann-Burchard reagent $(2.0 \mathrm{ml})$ was added and the mixture left to stand at room temperature for $20 \mathrm{~min}$. The absorbance of the mixture at $625 \mathrm{~nm}$ was read on an SP600 spectrophotometer. Standard solutions of ergosterol in chloroform were used to prepare a calibration curve.

Gravimetric determinations of total sterols. Total sterols in extracts obtained by the quantitative saponification procedure were determined gravimetrically as the digitonides as described by Longley, Rose \& Knights (I968).

Materials. Spectroscopic grade $n$-heptane (Fluka A.G.) was obtained from E. R. Emmanuel \& Co. Ltd, Wembley, Middlesex. Ergosterol, lanosterol, squalene and digitonin were purchased from Sigma (London) Chemical Co. Ltd. Nystatin (mycostatin) was purchased from E. R. Squibb \& Sons Ltd (U.K.), Wirrall, Cheshire. All solvents were of the highest purity available commercially. We are extremely grateful to the following for the other polyenes used: Dr B. Camerino, Farmitalia, Milan, Italy - etruscomycin (lucensomycin); Dr G. Kemp, Agricultural Division, American Cyanamid Co., Princeton, New Jersey, U.S.A. - pimaricin; Dr W. D. Celmer, Chas. Pfizer \& Co. Inc., Groton, Connecticut, U.S.A. - rimocidin sulphate (lot 4I 57-47-2); Dr G. B. Whitfield, The Upjohn Co., Kalamazoo, Michigan, U.S.A. - filipin III (U-25, 639). 


\section{RESULTS}

Mutant isolation and patterns of cross-resistance

The procedure outlined in Methods was followed using polyenes at the following concentrations: nystatin, I0, 20 and 30 units/ml (YCM and YMM); pimaricin, I0, 20 and $30 \mu \mathrm{g} / \mathrm{ml}$ (YCM); filipin, 5 and $10 \mu \mathrm{g} / \mathrm{ml}$ (YCM); etruscomycin 5 and $10 \mu \mathrm{g} / \mathrm{ml}$ (YCM); and rimocidin, Io and $20 \mu \mathrm{g} / \mathrm{ml}$ (YCM). The lowest concentration of each polyene was double that necessary to completely inhibit the growth of $\mathrm{pol}^{+}$in YCM. With the exception of nystatin in YCM, which yielded mutants from all tubes at all concentrations, the proportions of tubes yielding resistant mutants decreased with increasing concentration of antibiotic.

A total of 103 polyene-resistant mutants were obtained in this way. However, the isolation procedure was not very effective with etruscomycin and filipin. Cells which survived the procedure gave rise to clones which were clearly more resistant than $\mathrm{pol}^{+}$, but which could not be consistently scored as resistant on the selective polyene.

The basic patterns of cross-resistance demonstrated by the various groups of mutants are listed in Table I. All mutants, irrespective of the selecting polyene, are resistant to nystatin. Selection for etruscomycin or filipin resistance was equivocal, but it was an effective means of obtaining mutants resistant to other polyenes. The group of mutants selected on rimocidin exhibited the widest cross-resistance pattern, whilst selection with nystatin gave mutants with the least cross-resistance. A few mutants differed from these general patterns, but their subsequent analysis revealed no other distinguishing characteristics.

Table I. Cross-resistance patterns of groups of mutants isolated on specific polyenes

\begin{tabular}{|c|c|c|c|c|c|}
\hline $\begin{array}{l}\text { Polyene used } \\
\text { for isolation }\end{array}$ & $\begin{array}{c}\text { Etruscomycin } \\
(2.5 \mu \mathrm{g} / \mathrm{ml})\end{array}$ & $\begin{array}{c}\text { Filipin } \\
(\mathrm{I} \cdot 25 \mu \mathrm{g} / \mathrm{ml})\end{array}$ & $\begin{array}{c}\text { Nystatin } \\
(5 \text { units } / \mathrm{ml})\end{array}$ & $\begin{array}{l}\text { Pimaricin } \\
(\mathrm{I} \circ \mu \mathrm{g} / \mathrm{ml})\end{array}$ & $\begin{array}{l}\text { Rimocidin } \\
(2.5 \mu \mathrm{g} / \mathrm{ml})\end{array}$ \\
\hline Etruscomycin & $(+)$ & - & + & + & + \\
\hline Filipin & - & $(+)$ & + & - & - \\
\hline Nystatin (YCM) & - & - & + & - & - \\
\hline Nystatin (YMM) & - & - & + & - & - \\
\hline imaricin & - & - & + & + & - \\
\hline Rimocidin & - & + & + & + & + \\
\hline
\end{tabular}

$(+)=$ Isolated on this polyene but not conclusively resistant.

\section{Sterol absorption spectra}

The spectra of sterol extracts from resistant cells were of four types (Fig. I A, B, C, D) each differing from the wild-type pattern (Fig. I $\mathrm{pol}^{+}$). Two resembled those reported by Woods (I97I) for nys $I$ and nys 3 (see A and C in Fig. I) of the remaining two, B and D, the former indicates absence of absorbing sterols and the latter is identical to the absorption spectrum of pure ergosterol. All mutants with type ' $A$ ' pattern gave a growth medium extract (YCM) exhibiting a spectrum of the same type. The remaining mutants and $\mathrm{pol}^{+}$ gave medium extracts with no characteristic absorption suggesting that they did not excrete sterol.

\section{Genetic analysis}

Representative mutants of the four types of sterol pattern were crossed to $\mathrm{pol}^{+}$to test for dominance relationships, and to obtain the mutants in both mating,types. The diploids were all sensitive to nystatin and had $\mathrm{pol}^{+}$sterol patterns (Fig. I) indicating that the mutants were 


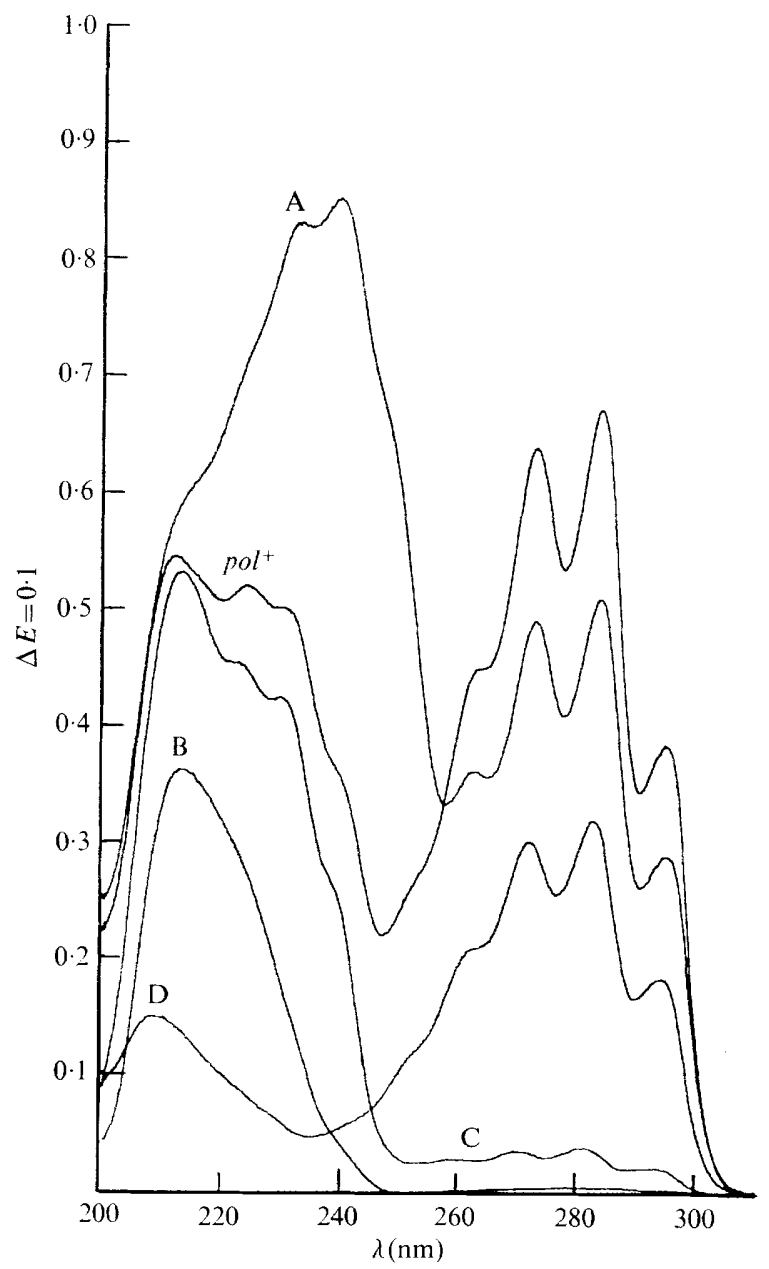

Fig. I. Ultraviolet absorption spectra of sterol extracts from wild-type and mutant strains of yeast. A, cell and medium extracts of pol $I ; \mathrm{B}$, cell extracts of pol $2 ; \mathrm{C}$, cell extracts of pol $3 ; \mathrm{D}$, cell extracts of pol 4 and pol $5 ; \mathrm{pol}^{+}$, cell extracts of wild-type.

recessive to $\mathrm{pol}^{+}$. All tetrads gave a 2:2 segregation for resistance to sensitivity, and all but one cross gave the expected segregation of two mutant and two $\mathrm{pol}^{+}$sterol patterns. The exception was a cross involving a mutant with type ' $\mathrm{A}$ ' sterol pattern which gave a normal segregation for resistance but some tetrads were abnormal in containing three sterol patterns, $\mathrm{pol}^{+}$, type A and type D. However, spore cultures with pattern D were sensitive to nystatin. Obviously the original A-type strain carried a double mutation. A backcross of this new polyene-sensitive strain with a mutant sterol pattern to $\mathrm{pol}^{+}$showed that the character segregated as a single recessive gene and it was decided to include it in subsequent genetic analysis.

Diploids from all possible pairwise combinations between these mutants were tested for resistance and sterol spectra. Five complementation groups were identified which we have called pol I to pol 5. The sterol patterns of the five loci are shown in Fig. I. The polyenesensitive genotype obtained from the above mentioned double mutant was allocated the 
Table 2. Gene allocation and polyene used for mutant isolation

\begin{tabular}{|c|c|c|c|c|c|c|}
\hline \multirow{2}{*}{$\begin{array}{l}\text { Polyene used } \\
\text { for isolation }\end{array}$} & \multicolumn{6}{|c|}{ No. of mutations } \\
\hline & pol I & pol 2 & pol 3 & pol 4 & pol 5 & Total \\
\hline Etruscomycin & - & I & - & - & 6 & 7 \\
\hline Filipin & 6 & I & $3^{*}$ & - & $16 *$ & 26 \\
\hline Nystatin (YCM) & 32 & 2 & I & - & I & 36 \\
\hline Nystatin (YMM) & II $*$ & I & 4 & $1 \dagger$ & - & 17 \\
\hline Pimaricin & - & $7^{*}$ & - & - & - & 7 \\
\hline Rimocidin & - & I & - & - & 9 & 10 \\
\hline Total & 49 & 13 & 8 & (I) & 32 & 103 \\
\hline
\end{tabular}

Table 3. Growth yields, u.v. absorption spectra and sterol contents of pol mutants

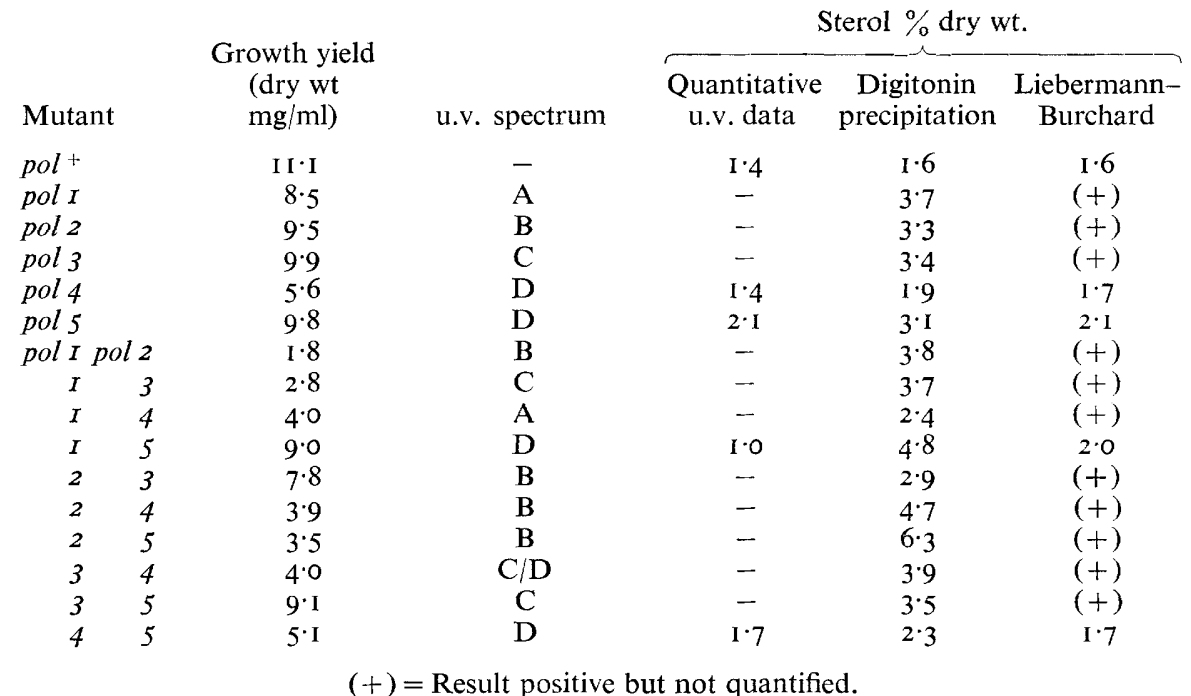

locus pol 4. Its spectrum is the same as that of resistant mutants allocated to pol 5 . No additional complementation groups were found in the crosses to untested mutants.

Crosses between standard mutants of pol $I$ to pol 5 were analysed for segregation of nystatin resistance (minimum of 10 tetrads), and sterol spectra (minimum of 5 tetrads) by the qualitative procedure. Recombination between genes was detected by the occurrence of $\mathrm{pol}^{+}$segregants. The ratio of parental ditype to non-parental ditype asci for all crosses approximated to $\mathrm{I}: \mathrm{I}$ indicating that none of the pol genes were linked.

Tetrads which contained $\mathrm{pol}^{+}$segregants should also contain double mutants, the reciprocal products of recombination. These were distinguished from single mutants by backcrossing members of such recombinant tetrads to $\mathrm{pol}^{+}$. Crosses involving single mutants only gave one type of mutant sterol pattern in the expected ratio of two mutants to two $\mathrm{pol}^{+}$. Double mutants gave a 3 : I ratio for resistance to sensitivity and both original mutant sterol patterns appeared.

Sterol spectra of the double mutants indicated epistasis between all pairs of pol mutants with the exception of pol 3/pol 4 and pol 4/pol 5 (see Table 3). The spectrum of the double 
Table 4. Cross-resistance patterns of standard single and double pol mutants

\begin{tabular}{|c|c|c|c|c|c|}
\hline Mutant & $\begin{array}{l}\text { Etruscomycin } \\
(2.5 \mu \mathrm{g} / \mathrm{ml})\end{array}$ & $\begin{array}{c}\text { Filipin } \\
(\mathrm{I} \cdot 25 \mu \mathrm{g} / \mathrm{ml})\end{array}$ & $\begin{array}{c}\text { Nystatin } \\
\text { (5 units } / \mathrm{ml})\end{array}$ & $\begin{array}{l}\text { Pimaracin } \\
(\text { I } \mu \mu \mathrm{g} / \mathrm{ml})\end{array}$ & $\begin{array}{l}\text { Rimocidin } \\
(2.5 \mu \mathrm{g} / \mathrm{ml})\end{array}$ \\
\hline $\mathrm{pol}^{+}$ & - & - & - & - & - \\
\hline pol $x$ & - & - & + & - & - \\
\hline pol 2 & - & - & + & + & + \\
\hline pol 3 & - & - & + & - & + \\
\hline pol 4 & - & - & + & - & - \\
\hline pol 5 & - & - & + & - & - \\
\hline pol I pol 2 & - & + & + & + & + \\
\hline $\begin{array}{ll}1 & 3\end{array}$ & - & + & + & + & + \\
\hline I 4 & - & - & + & - & + \\
\hline$I \quad 5$ & - & - & + & - & - \\
\hline 2 & - & + & + & + & + \\
\hline 2 & - & + & + & + & + \\
\hline 5 & - & + & + & + & + \\
\hline 3 & - & - & + & - & + \\
\hline 35 & - & + & + & - & - \\
\hline 45 & - & - & + & - & - \\
\hline
\end{tabular}

mutant $\mathrm{pol}_{3 / \mathrm{pol}} 4$ showed low, though typical 'ergosterol' peaks between 310 and $240 \mathrm{~nm}$, and a pol 3 peak at $230 \mathrm{~nm}$ reduced to a shoulder. The mutant pol 4/pol 5 and single mutants pol 4 and pol 5 gave indistinguishable spectra. Double mutants pol I/pol 3 and pol 3/pol 5 gave indistinct pol 3 spectra, but pol 3 may be considered epistatic in"both cases since no characteristic pol $\mathrm{I}$ or pol 5 absorption occurs. Only pol I/pol 5 gave a meaningful sterol spectrum from growth medium extracts. This strain resembles pol $I$ in that it excretes sterol, but in this case the pattern is similar to that obtained from cell extracts of pol 5 (Fig. I type D).

The genetic allocation and provenance of the 103 mutants are listed in Table 2. Only selection by nystatin and filipin results in mutations in pol I and pol 3. All five polyenes select mutations at pol 2 . Selection of mutations at pol 5 is apparently non-specific except for absence with pimaricin or nystatin in YMM. The most common mutations recovered $(80 \%$ of total) were pol $I$ and pol 5 .

\section{Cross-resistance of standard single and double mutants}

The resistance patterns of standard strains are shown in Table 4. Double mutants exhibit more cross-resistance than would be anticipated from the results for single mutants. For example, pol 3 although isolated on filipin is not conclusively resistant to it; however the double mutants pol I/pol 3, pol 2/pol 3 and pol 3/pol 5 are resistant to filipin. Resistance of all pol 2 double mutants to filipin was unexpected since the standard pol 2 was isolated on pimaricin and is itself sensitive to filipin.

\section{Sterol estimations on cell extracts of single and double mutant strains}

Although the ultraviolet absorption spectra are useful in"detecting sterol alteration in the pol mutants they can only be used to quantify ergosterol and $24,(28)$ dehydroergosterol. This procedure is valid for $\mathrm{pol}^{+}$; in addition we have applied it to the spectra of those strains which appear to contain only ergosterol, viz. pol 4, pol 5 and the double mutants pol $1 / \mathrm{pol} 5$ and pol 4/pol 5 (see column four in Table 3). The total sterol contents of all strains were determined gravimetrically as the digitonides and colorimetrically by the LiebermannBurchard reaction (Table 3). The sterol content of $\mathrm{pol}^{+}$is essentially constant when calculated by these three methods. Thus for this genotype we can conclude that ergosterol and 24,(28)- 
dehydroergosterol account for approximately $90 \%$ of the total sterol present and are indeed the major sterols of wild-type yeast. The ultraviolet absorption spectra of both pol 4 and pol 5 indicate the presence of a $\Delta 5,7$-diene sterol. If this sterol is ergosterol, then the sterol content indicated by the absorption spectra is appreciably lower in both strains than suggested by the alternative assays.

Extracts prepared from $\mathrm{pol}^{+}$and all single and double mutant strains gave a positive Liebermann-Burchard reaction. In all cases the end point was the standard green colour given by ergosterol. Since calculations based on an ergosterol standard are not applicable to extracts which did not contain ergosterol the majority of extracts are simply listed as giving a positive reaction.

All single mutants gave lower growth yield in stationary phase than $\mathrm{pol}^{+}$(Table 3 ), but only pol 4 shows a serious reduction $(50 \%)$. Out of the ten double mutants, only three, pol I/pol 5, pol 2/pol 3 and pol 3/pol 5 gave higher yields than pol 4, the single mutant with the lowest yield. The remaining seven gave yields ranging from $\mathrm{I} 6 \%$ to $46 \%$ of $\mathrm{pol}^{+}$.

\section{DISCUSSION}

These experiments show that resistance to a range of polyene antibiotics is associated with changes in sterol metabolism in yeast. Attempts to isolate mutants resistant to etruscomycin and filipin, two of the most potent polyenes, were only partially successful. Clones derived from cells which survived exposure to these two polyenes were not conclusively resistant to them but were resistant to nystatin. The isolation of mutants resistant to nystatin, pimaricin and rimocidin was more straightforward, though again all isolates proved to be resistant to nystatin.

The polyenes used in this study are known to differ in their ability to damage the fungal cell membrane (Kinsky, I970). In view of this it might be supposed that selection for resistance to particular polyenes might lead to specificity in terms of (i) cross-resistance to other polyenes; (ii) recovery of mutants at particular pol genes. Etruscomycin and rimocidin are most effective in selecting mutants cross-resistant to other polyenes (Table I) and are known to create considerable membrane damage, whilst nystatin, which causes little membrane damage, selects mutants which show very little cross-resistance. Filipin is an exception to this pattern since it is the most potent antibiotic used, but selects mutants with poor cross-resistance properties.

Survival after exposure to each polyene is correlated with mutation at particular loci (Table 2). The majority of mutants obtained with etruscomycin are allocated to pol 5, with filipin to pol 5, nystatin to pol $I$, pimaricin to pol 2 and rimocidin to pol 5 . This specificity probably reflects the binding potential of each polyene for the sterols in the cell membrane. Ergosterol and 24,(28)dehydroergosterol in $\mathrm{pol}^{+}$would be expected to bind all five polyenes; whilst, for example, the sterols in pol $I$ presumably have reduced affinity for nystatin but still bind the other polyenes sufficiently to cause membrane damage. Studies on the binding between specific polyenes and sterols obtained from the mutants are in progress. The data listed in Tables I, 2 and 4 suggest that there is a correlation between deficiency of u.v.absorbing sterols and cross-resistance, pol 2 being most deficient and most cross-resistant.

All of the single and double mutants contain proportionally more sterol than $\mathrm{pol}^{+}$. If these increases involve membrane sterol then they may be a contributory factor to resistance. It has been shown that alteration of the ergosterol content of yeast by changes in growth conditions does not lead to changes in polyene sensitivity (Lampen, Arnow \& Safferman, I960). However, it may be that the maximum ergosterol content of $I \cdot 3 \%$ used in this system 
was insufficient. Bulder (I97I) has shown that Schizosaccharomyces japonicus can grow anaerobically in the absence of ergosterol. Under these conditions cells contain $0.01 \%$ ergosterol, and are considerably more resistant to pimaricin than aerobically grown cells containing $0.24 \%$. Since sterol levels in the pol mutants are higher than this we think that reduction in binding of polyenes is a more probable cause of resistance.

The excretion of sterols by pol I mutants is a possible resistance mechanism. These sterols are able to complex with nystatin (unpublished results) and reduce the effective concentration of the antibiotic. Clearly, excretion of sterols is an interesting phenomenon and worthy of further investigation.

In addition to the information these mutants may yield concerning polyene resistance they may also allow a study of the biochemical genetics of sterol metabolism. If the u.v. absorption spectra may be considered a legitimate phenotype, the mutants clearly show epistasis and can thus be supposed to act in series rather than parallel. The epistatic relationships are consistent with the genes acting in the sequence:

$$
\text { pol } 2 \rightarrow \text { pol } 3 \rightarrow \text { pol } 5 \rightarrow \text { pol } I \rightarrow(\text { pol } 4 \text { ? }) \rightarrow \text { pol }^{+} \text {. }
$$

The position of pol 4 is not certain. It must come after pol 2 and pol $I$, cannot be detected in the presence of pol 5 and gives a 'mixed' spectrum with pol 3. Perhaps it is significant that pol 4 was isolated as a double mutant with pol $I$ and does not lead to resistance to any polyene. Nevertheless the majority of the data would place it after pol $I$ in the proposed sequence.

This interpretation of the epistatic interactions between the pol mutants is unfortunately inadequate to explain two other observations. Firstly, the sterol contents of the double mutants are in general higher than those of the parental single mutants, but it should be noted that the increases are not additive. Secondly, the double mutants show more extensive cross-resistance than the single mutants. Both of these observations suggest that the interactions between the pol genes are complex.

It may be that the pol mutants are defective in the regulation rather than the catalysis of sterol biosynthesis. The exact nature of the lesions may become clearer when we have more precise information on the sterols accumulated, and possible pleiotropic effects in other areas of metabolism. We anticipate that studies on the mutants will add to current knowledge of the physiological role of sterols and mechanisms of resistance to polyene antibiotics.

S.W.M. was supported by an S.R.C. Research Training Award.

\section{REFERENCES}

Adelberg, E. A., Roslansky, P. F., Myers, J. W. \& Coughlin, C. A. (1955). Attempted induction of microbial mutants requiring steroidal growth factors. Journal of Bacteriology 69, 733 .

AHmed, K. A. \& Woods, R. A. (1967). A genetic analysis of resistance to nystatin in Saccharomyces cerevisiae. Genetical Research 9, I79-193.

Andreason, A. A. \& Stier, S. J. B. (I953). Anaerobic nutrition of Saccharomyces cerevisiae. I. Ergosterol requirement for growth in a defined medium. Journal of Cellular and Comparative Physiology 4r, 23-26.

Breivik, O. N. \& OWADES, J. L. (I957). Spectrophotometric semimicro determination of ergosterol in yeast. Agricultural and Food Chemistry 5, 360-363.

Bulder, C. J. E. A. (1971). Anaerobic growth, ergosterol content and sensitivity to a polyene antibiotic, of the yeast Schizosaccharomyces japonicus. Antonie van Leenwenhoek 37, 353-358.

Hebeka, E. K. \& Solotorovsky, M. (1965). Development of resistance to polyene antibiotics in Candida albicans. Journal of Bacteriology 89, I 533-1 539.

KINSKy, S. C. (1970). Antibiotic interaction with model membranes. Annual Review of Pharmacology ro, I I9-I42. 
LAMPEN, J. O. (I966). Interference by polyenic antifungal antibiotics (especially nystatin and filipin) with specific membrane function. Symposium of Society for General Microbiology 16, I I I-1 30 .

LAMPEN, J. O., ARNow, P. M., BorowsKA, Z. \& LASKIN, A. I. (1962). Location and role of sterol at nystatinbinding sites. Journal of Bacteriology 84, I $152-1160$.

Lampen, J. O., Arnow, P. M. \& Safferman, R. S. (I960). Mechanism of protection by sterols against polyene antibiotics. Journal of Bacteriology 80, 200-206.

Littman, M. C., Pisano, M. A. \& Lancaster, R. M. (I958). Induced resistance of Candida species to nystatin and amphotericin B. Antibiotics Annual I957-8, 981-987.

Lomax, C. A., Gross, T. S. \& Woods, R. A. (197I). New mutant types at the ade 3 locus of Saccharomyces cerevisiae. Journal of Bacteriology 107, I-7.

LoNGley, R. P., Rose, A. H. \& KNIGHTS, B. A. (I968). Composition of the protoplast membrane from Saccharomyces cerevisiae. Biochemical Journal 108, 401-4I2.

MANNING, L. K. \& RoBERTSON, B. M. (1959). A case of aspergillosis treated with nystatin. British Medical Journal $\mathbf{x}, 345^{-3}-36$.

PAtel, P. V. \& Johnston, J. R. (1968). Dominant mutation for nystatin resistance in yeast. Applied Microbiology $16, \mathrm{I} 64-\mathrm{I} 65$.

ResNick, M. A. \& MorTimer, R. K. (1966). Unsaturated fatty acid mutants of Saccharomyces cerevisiae. Journal of Bacteriology 92, 597-600.

Stadtman, T. C. (1957). Preparation and assay of cholesterol and ergosterol. In Methods in Enzymology, vol. 3, pp. 392-394. Edited by S. P. Colowick \& N. O. Kaplan. New York: Academic Press.

Stanley, V. C. \& ENGLish, M. P. (I965). Some effects of nystatin on the growth of four Aspergillus species. Journal of General Microbiology 40, 107-I 18.

Stout, H. A. \& Pagano, J. F. (1956). Resistance studies with nystatin. Antibiotics Annual 1956, 704-710.

Woods, R. A. (1971). Nystatin resistant mutants of yeast: alterations in sterol content. Journal of Bacteriology ro8, 69-73.

Woods, R. A. \& Aнmed, K. A. (1968). Genetically controlled cross resistance to polyene antibiotics in Saccharomyces cerevisiae. Nature, London 218, 369-370.

ZyGMunT, W. A. \& TAvormina, P. A. (1966). Steroid interference with antifungal activity of polyene antibiotics. Applied Microbiology 14, 865-869. 